\title{
Wind energy versus natural gas in Latvia: policy evaluation with a System Dynamic simulation
}

\author{
A. Skujevska, F. Romagnoli, T. Zoss, I. Laicane, D. Blumberga \\ Riga Technical University \\ Institute of Energy Systems and Environment \\ Riga, Latvia \\ Agnese.Skujevska@rtu.lv
}

Received: May 12, 2019. Revised: May 15, 2021. Accepted: October 7, 2021. Published: November 15, 2021.

\begin{abstract}
To achieve national target proposed by the Renewable Energy Source Directive 2009/28/EC, to also accomplish to the $\mathrm{CO} 2$ emission reduction targets and to decrease the energy dependency Latvian government is planning to adopt different strategy policies such as feed-in tariffs (FITs) and capital subsidies, in order to incentive investor to use renewable based technology for power production
\end{abstract}

Neverthelss it is crucial to understand in long term perspective the effect and the costs of a specific policy (made even by the combination of different policy tools) applied to the energy sector.

Using this model, or an extended version of it, a cost/benefit analysis of a different set of policy scenarios can be carried out.

More in specific this study is driving its attention at a situation where it is possible to increase the share of wind power in the energy balance respect the use of natural gas as primary energy for power generation.

Four political instruments are chosen in this model: subsidies for construction of new wind-power facilities, information package at all power supply levels for risk reduction and reduction of maintenance costs through a learning effect.

The simulation period is from 2010 to 2110.

The analysis of policy instruments for development of renewable energy resources in power system illustrates wide potential of system dynamic modelling use for statement of priorities on power diversification.

The policy instrument of use of subsidies is a crucial priority. Feed-in tariff is not providing an evident. The reason of that can be related to the key aspect on the way Latvia is organizing its feed-in tariff policy.

Keywords- Wind energy, Feed-in tariffs, Governament subsidies, System dynamics.

\section{INTRODUCTION}

Sustainable development has always been an important part of of human life. [1] In accordance with European Union (EU) renewable energy resource strategy, which has been developed to conceive unified standard for Renewable energy resource usage and specify compulsory aims for end-use of renewable resources in overall energy resource and transportation fuel, increase of renewable energy resource usage in different economic sectors is becoming more and more important [2]. Directive states that $20 \%$ of energy resources in EU up to year 2020 must be covered by renewables [3]: wind power, solar power, geothermal, wave, tidal, hydro power, biomass, landfill gas, gas from waste water treatment plants and biogas $[4,5]$. The target set for Latvia is cover $42 \%$ of consumed energy with renewables till year 2020 [6]. Action plan to fulfil the target must be well thought and economically justified. Models that represent actual situation and possible scenarios are built for better understanding of electric power system and renewable energy resources integration possibilities $[7,8]$.

In Latvia renewable resource part in primary energy flow on year 2010 was $33 \%$. It means that it is necessary to define policy, which can increase renewable resource usage effectively to successfully achieve target, this is the aim of the model described in this paper.

\section{SYSTEM DYNAMIC MODELLING}

Researches made on electric power system scenarios have driven to the conclusion that the interaction of different energy resources and their applications is more complex than using nonlinear differential equation method that is commonly known as a standard when analyzing this kind of problems [7]. Systematic thinking is a way to analyze situation by both: looking at its general aspects and analyzing every part of system separately. System dynamics is a research method for complex system development which helps to solve such complex systems as electric power system evolution $[7,8,9]$.

System dynamics theory is based on research of relations between system behaviour and structure of the system itself $[8,10]$. The basis of system dynamics model is the mathematical definition of stocks and flows in the system that can be considered as internal or external variables identified the structure of a specific complex. Almost every stock has incoming and outgoing flows. One of the main advantages of system dynamics model is its graphically designed structure that can be easily understood. It is possible to include different feedback links in the model, which is important in a research of every process. Each action has its consequences and nonlinear effects can be identified, visualized and understood. 
Hence System dynamics model is a way to represent complex systems. Model can be adjusted for every problem, difference between various models is input data which has to be entered by user. Every element of system has to be connected with affecting element using the most precise link [8]. In this light a simulation using system dynamic modelling represent a good tool to understand and evaluate how a system is dynamically influenced by different policy scenarios.

For this reason a system dynamics model has been chosen for the evaluation of different policy measures within the Latvian electric power system development analyzing, at this stage, the most effective policy scenario on a proposed initial set for promoting the wind energy against usage of natural gas.

\section{PROBLEM FORMULATION}

The aim for Latvia which - stated by EU directive - is to produce $42 \%$ of all energy consumed by end user from renewables by year 2020, as it has been mentioned before. One of the largest sectors that influence this division is electrical power generation. Picture nr.1 shows that in year 2010 a large part of the electrical power was produced using imported natural gas.

In order to gain more independence in power production and produce electricity in environment friendly way it is necessary to increase renewable energy resource usage in electricity production.

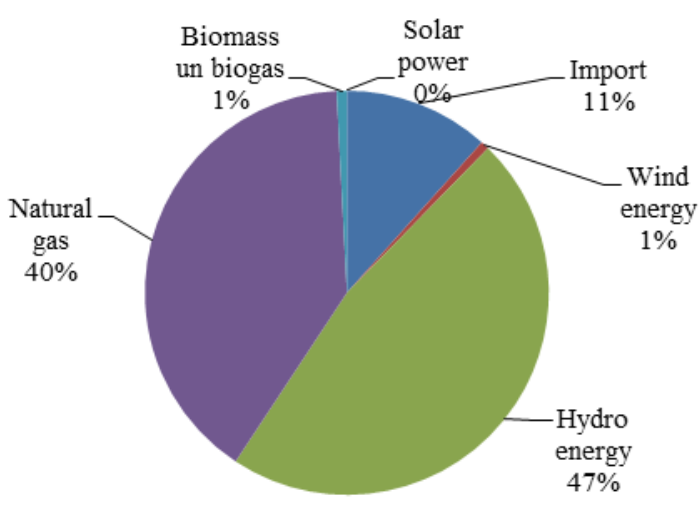

Fig. 1. - Energy sources distribution of electricity production in 2010 (Latvia)

Hence the aim of the model is to find new policy instruments which can increase renewable energy resource usage in electricity sector and in the same time the National costs for related to the implementation of a specific policy scenario.

\section{IDENTIFICATION AND DEVELOPMENT OF THE PRINCIPAL DYNAMIC HYPOTHESIS}

The program Powersim Constructor was used to represent concurrent situation in electricity production and to create the model. Renewable energy resources are represented by wind power which is opposed with electricity produced by natural gas. Main elements in model are: installed wind power and installed natural gas electricity production power [11]. Each element has one incoming and one outgoing flow. Incoming flow describes investment (GW/year), outgoing flow is depreciation per year (GW/year). Picture nr.2 represents basic structure of stock and flows related to each Installed capacity for power generation (i.e. natural gas and wind).

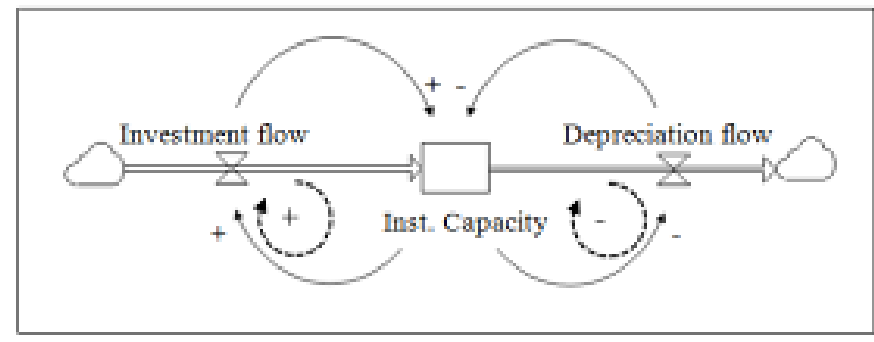

Fig. 2. - Primary Stock-flow diagram representing the relationship between the stock of the total capacity of installations against investment and depreciation flows [12].

Data is gathered from year 2010 (reference year in the model), when the installed wind power was $0,03 \mathrm{GW}$ and installed natural gas electricity generation power was 0,95 GW. In order to change this situation new instruments that can affect installed power size are introduced and implemented into the model.

\section{MODEL STRUCTURE AND ELEMENTS}

The central element of the proposed model is mainly related to the idea of stocks representing the installed power capacity related to wind technologies and natural gas technologies. This process is represented as a feedback link from equipment wear out to total investment.

Within the model it was assumed that the capacity of installed facilities is influenced by: investments and depreciation of the equipment over the time that. Each of the installed capacity stocks was linked with two flows representing in-flows aiming to increase the capacity of installed power facilities and out-flows representing the depreciation (related to the life-span of the technology used) that is reducing the value of total installed capacity.

Figure 2 represents the stock-flow structure using system dynamics modeling elements valid for each type of installed capacities. The installed capacity of each technology represents the proportion of a particular used technology in the power system considered. The larger the capacity is, the larger becomes the investment flow (a positive reinforcing loop takes place). But, also, the larger the capacity is, the larger becomes the depreciation flow decreasing meantime the stock of the installed capacity (a negative counteractive loop takes place). This is the way how the nodal part of the model works. This type of combination defined a typical S-shape dynamic behavior that is possible to detect in the final results.

The installed capacity is influenced by the costs for power energy production depending on the technology investment and maintenance costs, the risks costs and the price and quality of the fuel (only for natural gas).

In order to understand the behavior of switching to wind based technologies over the time, the model was based on a dynamic "equilibrium" principle. This means that the entire 
installed capacity is assumed constant over time with a value equal to $0.98 \mathrm{GW}$.

It could be also assumed that the behavior of the observed system in the reference mode was formed by the interaction of the investment and depreciation flows, and the capacity stock.

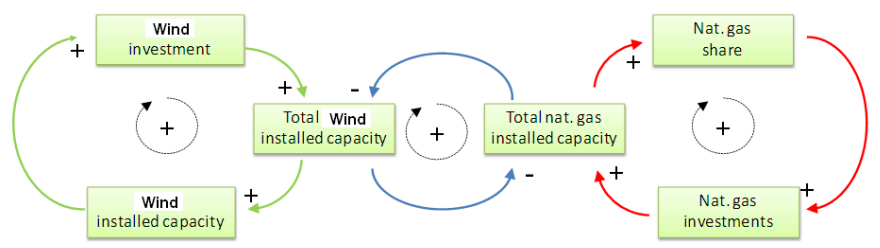

Fig. 3. - Casual loop diagram of the main structure of the model reference to the total installed capacity.

In reference to the previous figure 3 the green casual loop represents the total installed capacity of wind-based power. These show that the larger the investments for wind technology are the larger are the installed capacities and consequently the shares of wind technology for power generation. The central blue loop shows that an increase of the total installed capacity for wind-energy defines a decreased in the total installed capacity of natural gas installations in order to guarantee the constant production of production that is the assumption of the model. This reinforcing is the main reason connected to the explanation of the tendency of the wind technology to naturally increase over time.

Hence the main aim of the model is to create a suitable mechanism which could show necessary investment for wind generated power at defined year.

The general structure of the system dynamics model is illustrated in Figure 4.

The stock wind capacity represents the installed capacity of wind-power production. An element is given an initial value to describe the current installed capacity of wind-based energy and is dependent on the annual amount of power produced; the initial share of wind is equal to $3 \%$

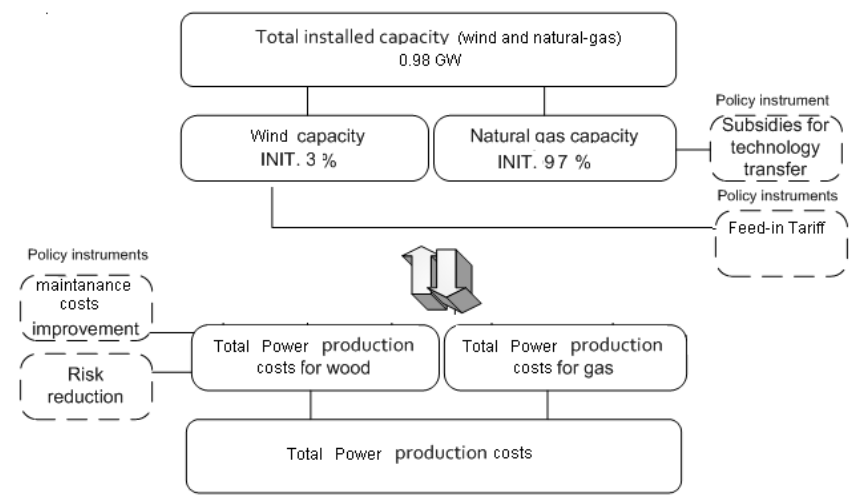

Fig. 4. - Structure of the model
The impacts different policy instruments have been analyzed within the proposed system dynamics model as well as their combination. The following policy instruments were considered:

- Subsidies - a policy instrument that provides subsidies for replacement of natural gas installations with wind technology $\left(\mathrm{P}_{\mathrm{SUB}}\right.$, reference to table 1$)$.

- Risk reduction - a policy instrument that comprises an initial short-term campaign to compensate risks related to the use wind technology. The aim of the policy instrument is to encourage the public to choose wind-fired technologies. It indicates marketing or support measures to initiate the process of disseminating positive experiences of wind-base power use due to information flow $\left(\mathrm{P}_{\mathrm{R}}\right.$, reference to table 1$)$.

- Cost maintenance improvements - i.e. R\&D measures $\left(\mathrm{P}_{\eta}\right.$, reference to table 1 ).

- Feed-in Tariff (FIT) application - policy measure paid by government to promote wind energy applied as percentage of the total production costs of wind installation $\left(\mathrm{P}_{\mathrm{FEED}-\mathrm{IN}}\right.$, reference to table 1 ).

Risk reduction and cost maintenance improvement tools have been simulated with a "learning-effect" on cumulating experiences on using wind technologies in the society. The effect of subsidies is introduced as a learning effect but in the same directly acting on the total power production costs for wind.

For precise definition of equipment depreciation the following formula is used (formula nr.1):

$$
\mathrm{Wear}=\mathrm{P} / \mathrm{T}_{\text {eq }}
$$

Where:

Wear - equipment depreciation (GW/year)

$\mathrm{P}$ - Installed power $(\mathrm{GW})$

T eq. - actual equipment run time (years)

Policy instruments impact equipment run time which is described with formula nr. 2:

$$
\mathrm{T}_{\text {eq. }}=\mathrm{T}_{\text {ref }} \cdot \text { Subs } \cdot \text { Feedin } \text { eff }
$$

$\mathrm{T}_{\text {eq }}$, - actual equipment run time (years)

$\mathrm{T}_{\text {ref }}$ - reference time of equipment run time. Normally it is assumed to be 20 years, but it can vary in different regions and systems.

Subs - wind power subsidies effect on equipment run time.

Feedin $_{\text {eff }}-$ Feed-in tariff effect on equipment run time

Since most of the produced energy is measured in MWh and data for every region is defined in the same way it is 
necessary to specify work hours per year. To avoid situation when actual work hours could affect the model, they should be specified in the same way for both electrical power generation methods. One of possible solutions is to calculate overall average in specified region from total work hour amount on wind power generation equipment and natural gas power generation equipment. Since total amount of produced energy is fixed it is possible to derive work hours, for year 2010 average between these two numbers is 2443,82 hours. Produced energy is calculated according to formula nr.3

$$
\mathrm{E}=\mathrm{P} \cdot \mathrm{t}
$$

$$
\begin{aligned}
& \text { E - produced energy }(\mathrm{GWh} / \text { year }) \\
& \mathrm{P} \text { - installed power }(\mathrm{GW}) \\
& \mathrm{t} \text { - work hours (h/year) }
\end{aligned}
$$

The total produced energy is a sum of power generated from wind and that from natural gas. In this model it is assumed that produced power is a constant and it is equal to sum of power produced by natural gas and wind in year 2010 .

In the model two factors that affect choice are deeply analyzed, those are - wind and natural gas electrical power production tariffs. Both tariffs are affected by:

- $\quad$ Capital costs (EUR/MWh);

- $\quad$ Operating and maintenance costs (EUR/MWh);

- Fuel costs (for wind power generation it is 0 EUR/MWh);

- $\quad$ reference time of equipment run time (year);

- $\quad$ production efficiency;

- natural gas combustion heat (for natural gas electrical power production tariff, $\mathrm{MWh} / 1000 \mathrm{~m}^{3}$ );

- Real interest rate.

\section{USE OF POLICY INSTRUMENTS}

It is necessary to create policy instruments that affect investment for power increasing to compare different scenarios. All used instruments are created in a way that end user can add or remove them from model according to his needs. This function is necessary so that user can evaluate impact and interaction of different policy instruments with other policy instruments. There is a detailed explanation on how every instrument is applied into model furthermore.

\section{A. Instrument for risk reduction}

Instrument for risk reduction is introduced to find out what impact has experience of wind power usage to reduce risks. Social campaigns have to be made to inform society according to this instrument. Greater emphasis should be put to inform businessman and potential power plant designers and builders. Instrument for risk reduction predicts that by increase of wind power generation, risks related to new wind power plant building and operation will reduce.
It is necessary to create new stock - wind power consumption, to introduce this instrument. Initial size of this stock is $0 \mathrm{GWh} /$ year, because it is assumed that instrument for risk reduction starts on reference year. Since incoming flow is directly related to generated wind power this value will increase with every produced GWh starting from reference year. New component is introduced - experience for risk reduction, which is calculated according to formula nr.4:

$$
\operatorname{EXP}_{\mathrm{R}}=\mathrm{e}^{- \text {Eprod/(Einit. }} \mathrm{t}_{\mathrm{R}} \text { ) }
$$

$\mathrm{EXP}_{\mathrm{R}}-$ experience in risk reduction

$$
\mathrm{E}_{\text {prod }} \text { - consumed wind power }(\mathrm{GWh} / \text { year })
$$

$\mathrm{E}^{\mathrm{init}}$ - consumed wind power initial value (GWh/year)

$t_{R}$ - time till $63 \%$ risk reduction. In this module it is assumed to be 10 years.

Experience affect to risk reduction is linked with element that can enable or disable policy instrument. This value can be 0 in a scenario when risk reduction instrument is not used or 1 when this instrument is used. For wind energy tariff this instrument is connected as a separate complement.

\section{B. Instrument for efficiency increasing}

Instrument for efficiency increasing is a way to evaluate experience effect on new technology development [13]. Efficiency of wind power generation equipment increases in the course of time when this instrument is enabled. This instrument is related with information flow. The faster information about improvements in technology is given to potential wind power plant designers and other society members, the faster increases investment for wind generation power enlargement. Another factor is power enlargement of already existing wind power plants by use of new technological solutions.

Instrument for efficiency increasing is related to wind power consumption stock just like instrument for risk reduction. Effect of experience on efficiency increase is calculated according to formula nr.5.

$$
\operatorname{EXP}_{\text {Ef }}=\mathrm{e}^{- \text {Eprod/(Einit . tef) }}
$$

$\mathrm{EXP}_{\mathrm{Ef}}$ - experience effect on efficiency increase,

$\mathrm{E}_{\text {prod }}$ - consumed wind power $(\mathrm{GWh} /$ year)

$\mathrm{E}^{\text {init }}$ - consumed wind power initial value $(\mathrm{GWh} /$ year $)$

$t_{E f}-$ time till $63 \%$ efficiency increase. In this module it is assumed to be 100 years. Period length is based on knowledge that efficiency improvement is long lasting process and more time is necessary than in risk reducing process.

It is necessary to calculate wind power generation equipment efficiency to attach this instrument to the model. Calculation can be seen in formula nr.6.

$$
\begin{aligned}
& \mathrm{Ef}_{\text {sum }}=\mathrm{Ef}_{\text {wind eq. }}+\left(1-\mathrm{Ef}_{\text {wind eq. }}\right) \cdot\left(1-\mathrm{EXP}_{\mathrm{Ef}}\right) \cdot \mathrm{Ef}_{\mathrm{INSTR}} \\
& \mathrm{Ef}_{\text {sum }}-\text { wind generation equipment efficiency }
\end{aligned}
$$


$\mathrm{Ef}_{\text {wind eq }}$ - wind generation equipment efficiency prognosis, which is defined by " $\mathrm{S}$ " type trend line. This trend is used if efficiency increasing instrument is disabled.

$\mathrm{EXP}_{\mathrm{Ef}}$ - experience effect on efficiency increase,

$\mathrm{Ef}_{\text {INSTR }}$ - Management variable for efficiency increasing instrument. If value of this parameter is 0 , instrument is not used. Whereas instrument is used and all before mentioned processes are in place if value is 1 .

This instrument is connected as a separate complement in wind energy tariff, maintenance and operation costs are divided with wind generation equipment efficiency.

\section{Subsidies instrument}

Subsidies instrument is working as a finance instrument which can attract interests for wind energy increase. Subsidies instrument size that is used in the model can be regulated by adjusting it to achieve necessary effect or in accordance to available resources. Subsidies instrument gives certain input to wind generated energy tariff. In model it is assumed to be $20 \%$.

Two management components (enabling/disabling) are added to model for subsidies instrument. First of them reacts in tariff scheme and is included in formula $\mathrm{nr} .7$ for subsidies calculation.

$$
\mathrm{SUB}_{\text {Tar. }}=\text { Fin } \cdot \mathrm{SUB}_{\text {TarINSTR }}
$$

SUB $_{\mathrm{Tar}}$ - Subsidies which cover part of wind generation power tariff.

\section{Fin - part of finances in wind generation power tariff}

SUB $_{\text {TarINSTR }}$ - management variable for subsidies instrument. If value of this parameter is 0 , instrument is not used. If SUBTarINSTR $=1$ part of wind generation power tariff is covered according to specified values.

Since usage of subsidies is related to knowledge of society it is necessary to create additional management component that is added to control wear-out speed, which reflects over-all situation. This component is switching on and off according to before mentioned variable. If value of this component is 0 no subsidies for equipment change from natural gas power generation equipment to wind power generation equipment are given, if this value is 1 subsidy for equipment change are given. Component is attached in model before calculation of equipment life time, in this way it is possible to increase or decrease each equipment life time.

\section{Feed-in tariff instrument}

There is fixed feed-in tariff for every kind of produced electric power $[10,11]$. For this reason it is necessary to include feed-in tariff in model to see how it affects selection of production solutions. Difference between feed-in tariff and production costs is compared in the model. Production method that has bigger difference is more attractive from economical point of view and for investors. Relation of difference between feed-in tariff and production costs and, for example, wind energy production costs, is called return of investment [14]. By comparison of wind and natural gas energy return of investment it is possible to model desire to use wind power generation equipment against over-all desire to use electricity generation equipment.

It can be seen from the picture nr. 4 that desire to use wind power generation equipment increases because of natural causes, by year 30 to 40 starting from reference year desire to use wind power generation equipment decreases rapidly. It can be explained because according to MK law Nr. 221 combined heat and power (CHP) procurement price energy component is directly related to natural gas final trade tariff without added value defined by market regulator in accordance to natural gas consumption amounts and electrical power installed in CHP plant [15].

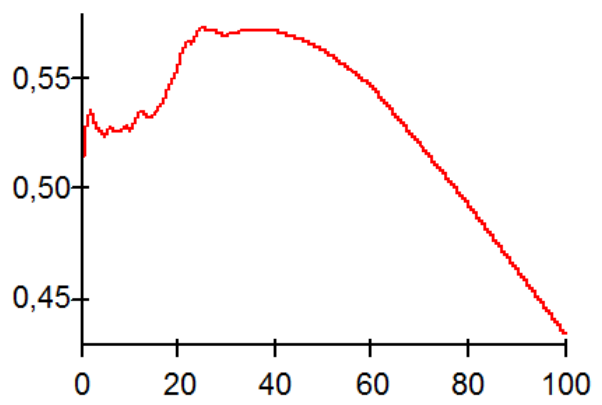

Fig.4. Desire to use wind generated power against over-all desire to use electricity generation equipment

Since price of natural gas is increasing, but feed-in tariff of wind generated power is constant [16], it happens that in a longer period feed-in tariff instrument increases power generated by natural gas power plants.

\section{SCENARIO MODELING}

By a variation of different policy instruments it is possible to evaluate their impact to electric power production system. Different development scenarios were produced in accordance with various policy instruments. These scenarios are summarized in table 1 .

Development scenarios for Latvian electricity systems changes

\begin{tabular}{|c|c|c|c|c|c|}
\hline Scenarios & $\begin{array}{l}\text { Name of } \\
\text { tool }\end{array}$ & $P_{R}$ & $P_{\eta}$ & $P_{\text {SUB }}$ & $P_{\text {FEED-IN }}$ \\
\hline $\begin{array}{l}\text { 1. Base scenario (,,business- } \\
\text { as-usual") - no one policy } \\
\text { instrument used }\end{array}$ & $\mathrm{BS}$ & 0 & 0 & 0 & 0 \\
\hline 2. Only feed-in tariff is used & $\begin{array}{l}\text { SC1_FE } \\
\text { EDIN }\end{array}$ & 0 & 0 & 0 & 1 \\
\hline 3. Only subsidies are used & $\begin{array}{l}\mathrm{SC} 2 \_\mathrm{SU} \\
\mathrm{B}\end{array}$ & 0 & 0 & 1 & 0 \\
\hline $\begin{array}{l}\text { 4. Only energy efficiency is } \\
\text { used }\end{array}$ & SC5_EFF & 0 & 1 & 0 & 0 \\
\hline $\begin{array}{l}\text { 5. Only risk reduction is } \\
\text { used }\end{array}$ & $\begin{array}{l}\text { SC6_RIS } \\
\text { K }\end{array}$ & 1 & 0 & 0 & 0 \\
\hline $\begin{array}{l}\text { 6. Combination } 1 \text { of the } \\
\text { policy instruments }\end{array}$ & $\begin{array}{l}\text { SC3_BE } \\
\text { ST2 }\end{array}$ & 1 & 0 & 1 & 0 \\
\hline
\end{tabular}




\begin{tabular}{|l|l|l|l|l|l|}
\hline $\begin{array}{l}\ldots \text { i Combination of policy } \\
\text { instruments }\end{array}$ & SC.. &.. &.. &.. &.. \\
\hline $\begin{array}{l}\text { n. All policy instrument } \\
\text { implemented }\end{array}$ & SC4_all & 1 & 1 & 1 & 1 \\
\hline
\end{tabular}

\section{POLICY STRATEGY EFFECTS: ANALYSIS OF RESULTS}

Among all the possible combination of the policy tools for the sake of visualizing have been selected 5 policy scenario.

Figure 1 summarizes the comparison among a set of the 5 different types of dynamic behaviors associated to specific policy scenarios chosen for this section (BS, SC1 FEEDIN, SC2_SUB, SC3_BEST2, SC4_all).

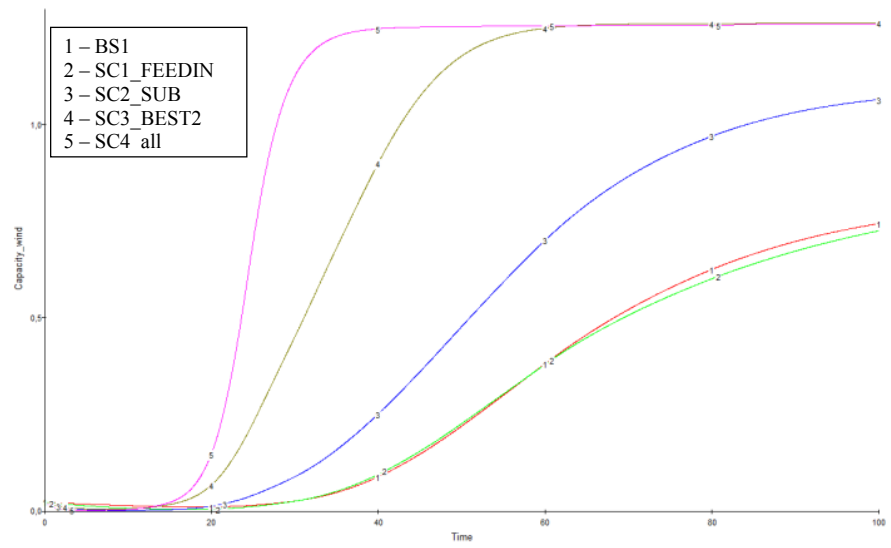

Fig.5. Comparison of installed capacity of wind-based electrical energy production for different scenarios expressed in GW

Three different types of trends can be identified. The first one defines a non-linear relationship related to the implementation of the policy with a trend close to the base scenario (BS) behaviour (line 2 in figure 5). The second one, always with a non-linear tendency, reveals a moderate increase of the wind sector respect the BS scenario (line 3 in figure 5). The third one where there is an important non-linear increase in the use of wind against the use of natural gas for the electric energy production (lines 4 and 5 in figure 5).

From a general overview it can be seen that a positive effect in terms of increase of the share of wind-power is present also in the BS scenario where despite none of the mechanism are implemented after 100 year the share of the wind-energy respect natural gas-based electric energy production reaches the level of circa $40 \%$.

More in specific one can see that the effect of subsidies for promoting the use of wind as wind as source for production of electric energy (constant over time with a value of $20 \%$ ) is the most effective tool in a long term perspective (line 3 in figure $5)$.

Nevertheless from figure 5 it can be also understood that, except for the scenario SC4_all, all the policy tools and the combination of them implement in different policy scenarios show a willingness of the Latvian operators to not invest in wind-energy before 20 years. This aspect shows that even in the light of a theoretical favourable condition for investments in the wind energy sector (i.e. promotion of subsidies, feed-in tariff and measures aiming on decrease of the investment risk) there is a delay of the positive effects probably due to the socalled "inconvenience costs" that keep still high the costs related to a front-up investment in the wind sector (see figure 2).

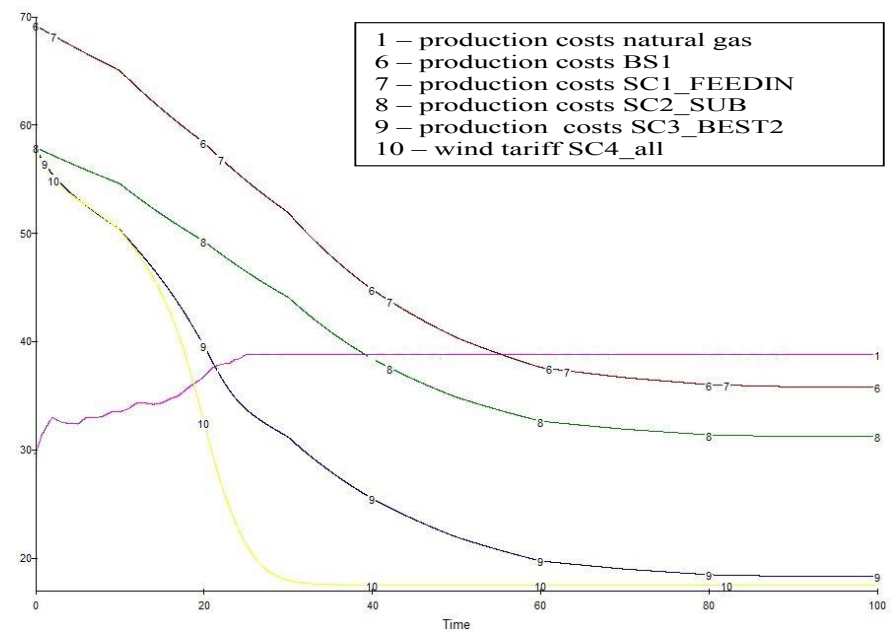

Fig.6. Comparison of electric energy production costs for different scenarios expressed in $€ / \mathrm{MWh}$

Looking trough the outcomes from the figure 6 is possible to determine form the model the "learning curves" in the wind system for different policy scenarios. As it can be seen there are 2 types of initial starting points of the wind-power production costs, this is related to the application of subsidies. The natural tendency of increasing the share of wind-power investment in the base scenario is reflected in correspondent decreasing of the costs for production that anyway only 70 years they are halved.

Moreover another important aspect outlined from the results is reference to the scenario SC1 FEEDIN. As described in the previous chapter for the Latvian legislation [16] is foreseen feed-in tariffs for wind-power constant over time according to a fixed price model within a marketindependent policy view [17] while the tariff for natural gas operators presents a variable increasing value (see Figure 3 ).

This seems a contradiction in terms, in fact having constant feed-in tariff and increasing tariff according to Latvian Directive is not favourable for development of the installed wind capacity, but from RES directive and in reference to what is outcomes from other study $[14,17]$ feed-in tariff represent one of the main tool (together with subsidies and rebates) to promote and incentive installation of RESbased power stations. Consequently this is the reason why in the analyzed case the effect of the feed-in tariff is neglected for long term perspectives. 


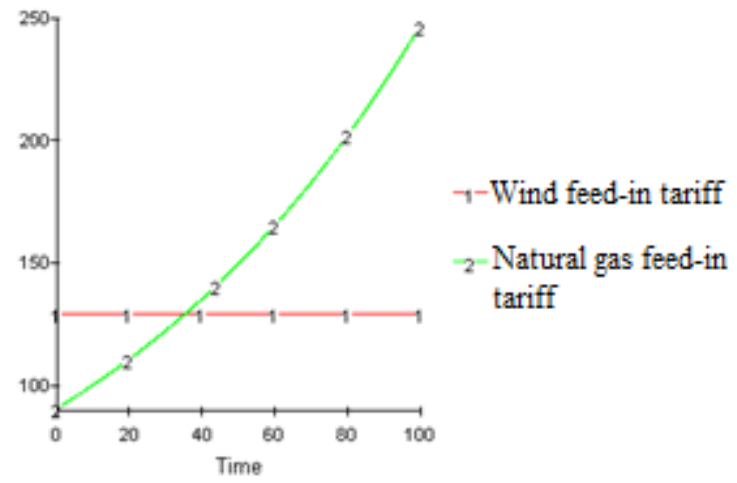

Fig.7. Feed-in Tariff for wind-power and tariff for natural gas ( $€ / \mathrm{MWh})$

Even though from figure 7 is possible to identify a minimal beneficial effect on the willingness of investor to be oriented on wind-energy (see figure 7 with reference to line 2 respect line 1) but as also previous mentioned in a long terms perspective in the light of an higher value of the return of investment (ROI) this effect is attenuated. This consequence is basically justifying the dynamic output described in the chapter "Feed-in tariff instrument" in figure 4.

\section{DISCUSSION}

The use of a system dynamic modeling within the evaluation of the Latvian energy strategy on promoting RESbased power production is an appropriate method since is providing a good tool for the evaluation of different policy effects and the cost of their application.

In fact energy and economical analysis together with energy sector modeling at Latvian State level use different types of mathematical/economic models with different initial data and/or assumptions. Within this aspect system dynamic modeling represents a powerful flexible tool taking into account variables from economic, policy, social and environmental point of view.

In the Latvian context there is a lack of adequate longterm state support scheme and very low perception of the real beneficial environmental benefit on using renewable technology from both investors and community. This aspect could be crucial in the light of tackling climate change processes. In this context is lying down the reason of a long perspective analysis proposed in this study

Beside the target fixed in the EU RES Directive as well for Latvia there is the main objective to increase the proportion of renewable energy sources in the power generation sector with the proper implementation of the best policy strategy. In this light it is crucial the target related to reducing greenhouse gas emissions with the theoretical minimal costs for the community and guarantying a stronger fuel independency.

In regard to the results carried out within this study if the key target for the Latvian power strategy is a fast implementation of a bigger amount of wind-based installed capacity the strategy has to implement at least subsidies.

In the other hand this solution can be the most economical aggressive also for the National strategy with the consequences on increasing the risk of massive investment in only this direction.

An important comment should be devoted to the feed-in tariff instrument. In fact as shown in the chapter of results this tool is not providing evident effect in both short and long terms perspective. The reason of that can be related to the key aspect on the way Latvia is organizing its feed-in tariff policy.

In fact as mentioned wind-energy FIT in Latvia are market-independent foreseeing a known as fixed-price with a fixed price for electricity delivered to the grid. In this way the fixed price is independent from other economical variables.

In this light the all FIT strategy can be think to be organize under two aspects: the first related to an evaluation of a possible FIT system market-dependent and the second related to the evaluation how the feed in are related and evaluated respect the value on which tariff for natural gas-based power is calculated.

Moreover in terms of optimizing the implementation of subsidies together with feed-in tariff in the national energy strategy a dependency of the FIT price based on the size of the subsidies awarded can be established [9] (i.e. decreasing in time)

In order to produce a positive effect, acting on reducing the wind-power production costs based real or perceived negative impacts, the accumulation of positive experiences is crucial for reducing the risk perception of potential wind investors.

Although in this study authors present the changing share among wind-power and natural gas-based power, it is possible in further improve the modeling in the following points:

- Integrating in the same type of structure of the model the whole sources for power generation in Latvia both RES and fossil based, taking into account as well power imports;

- Including other policy instruments and assessing their impacts (i.e. effect of a $\mathrm{CO} 2$ taxation as well the Emission Trading Scheme);

- including sustainable criteria taking into account resources available to Latvia;

- Re-modulate a possible policy scenario where FIT is a market-dependent variable and will foresee a correlation with subsidies awarded [9];

- Including a sensitivity analysis and validation of the mode;

- the attention should be also focused in relation to the demand of energy in the future and could be think as an external variable depending from different parameters. At the moment the assumption have been taken to keep constant over time.

- Choosing an electric demand not constant over time. 


\section{CONCLUSIONS}

As general outcomes:

- The model proposed model has been applied to the Latvian power system in reference to wind-power and natural gas-based power generation. The aim of the model is to evaluate which policy instrument can play a prominent role in the switch to a wind-system and more in general on RES power production system. The model proposed an analysis within 100 years.

- The policy instruments have been implemented in terms of: i) subsidies ii) promoting and improving the dissemination of best practices and campaigns for the use of wind technology decreasing risk perception, and iii) improvement of the learning curve for the maintenance cost based on the increase of the installed capacity; iv) feed-in tariff.

- The analysis of policy instruments for development of renewable energy resources in power system illustrates wide potential of system dynamic modeling use for statement of priorities on power diversification.

- The model proposed is a reliable and valuable tool for the comparison of different RES-source for electric power in comparison with fossil based electric energy by the application of various policy strategies.

- From the model is possible to evaluate the cost of $\mathrm{CO}_{2}$ emission reduction related to a certain implemented strategy.

- The tool is providing the possibility to evaluate as well the economic cost for a State electric energy strategy.

- The structure of model can be applied to a system involving the whole Latvian gross electricity production system (including as well the import) and/or to a wider frame.

As specific outcomes:

- The policy instrument of use of subsidies is a crucial priority.

- Feed-in tariff is not providing an evident. The reason of that can be related to the key aspect on the way Latvia is organizing its feed-in tariff policy.

- At this stage the whole model has been based on the comparison between the wind energy sector and the natural-gas based electricity production system. The total installed capacity (wind plus natural-gas) have been consider constant and equal to $0.98 \mathrm{GW}$ assuming a consequently a constant demand.

- Among the strategy implemented the investment cost are still high defining important increase of the share of wind-power only after 15 years

- The average electric power production can be seen as benchmark tariffs.

\section{ACKNOWLEDGMENT}

This work has been supported by the European Social Fund within the project "Support for the implementation of doctoral studies at Riga Technical University" and Nordic Energy Research project "NORSTRAT" (project No 4000764).

\section{REFERENCES}

[1] Momete D. C. "Sustainable Development and its Concrete Implications: From an Ancient Wisdom to a Modern Fashion" in 11th WSEAS International Conference on environment, ecosystems and development. Brasov, Romania, June 1-3, 2013

[2] Kostic M. "Energy and Environment: Fundamentals, Challenges and Potentials" in 7th WSEAS International Conference on energy and environment. Kos Island, Greece, July 14-17, 2012.

[3] Westholm E., Beland Lindahl K. "The Nordic welfare model providing energy transition? A political geography approach to the EU RES directive" in Energy Policy, issue 50, 2012, 328 - 335.

[4] Skoglund A., Leijon M., Rehn A., Lindahl M., Waters R. "On the physics of power, energy and economics of renewable electric energy sources - Part II" in Renewable Energy, issue 8, 2010, 1735 - 1740

[5] Leijon M., Skoglund A., Waters R., Rehn A., Lindahl M. "On the physics of power, energy and economics of renewable electric energy sources - Part I" in Renewable Energy, issue 8, 2010, 1729 - 1734

[6] Toke D. "The EU Renewables Directive-What is the fuss about trading?" in Energy Policy, issue 8, 2008, 3001 - 3008.

[7] Alishahi E., Parsa Moghaddam M., Sheikh-El-Eslami M.K. "A system dynamics approach for investigating impacts of incentive mechanisms on wind power investment" in Renewable Energy, issue 37, 2012, 310 317.

[8] Blumberga A. System dynamics for environment engineering students, RTU Institute of Energy Systems and Environment, Riga, 2010, vol. 318

[9] Cavana1 R.Y. "Modeling the environment: an introduction to system dynamics models of environmental systems" in System Dynamics Review, issue 2, 2003, 171-173.

[10] Cavana1 R.Y., Ford A. "Environmental and resource systems: Editors' introduction" in System Dynamics Review, issue 2, 2004, 89 - 98.

[11] Romagnoli, F., Dzene, I., Barisa, A., Blumberga, D., Blumberga, A., Davidsen, P., Moxnes E. "The Use of System Dynamics Approach for Assessing the Impacts of Policy Measures and Strategies on Wood Energy Market Development in Latvia" in 3rd International Symposium on Energy from Biomass and Waste. Italy, Venice, 2010.

[12] Romagnoli, F., Barisa, A., Blumberga, A., Blumberga, D., Dzene, I., Rošā, M., Rochas C. "Policy strategy effects for a sustainable improve of a wood-based energy structure in Latvia: an integrated dynamic model of the district heating system" in 20th European Biomass Conference and Exhibition. Italy, Milan, 2012.

[13] Snow R. "Transitioning to a Renewable Energy Economy" in 7th WSEAS International Conference on energy and environment. Kos Island, Greece, July 14-17, 2012.

[14] Hsu C.W. "Using a system dynamics model to assess the effects of capital subsidies and feed-in tariffs on solar PV installations" in Applied Energy, issue 100, 2012, $205-217$.

[15] The rules for electricity production and pricing, Cogeneration: Cabinet of Ministers Regulations No.. 221, in Latvijas Vēstnesis, issue 42, 2009.

[16] The rules for the production of electricity from renewable energy sources, and pricing arrangements: Cabinet of Ministers Regulations No.. 262, in Latvijas Vēstnesis, issue 51/52, 2010.

[17] Toby Couture, Yves Gagnon "An analysis of feed-in tariff remuneration models: Implications for renewable energy investment" in Energy Policy, issue 38, 2010, 955 - 965.

\section{Creative Commons Attribution License 4.0 (Attribution 4.0 International, CC BY 4.0)}

This article is published under the terms of the Creative Commons Attribution License 4.0 https://creativecommons.org/licenses/by/4.0/deed.en US 